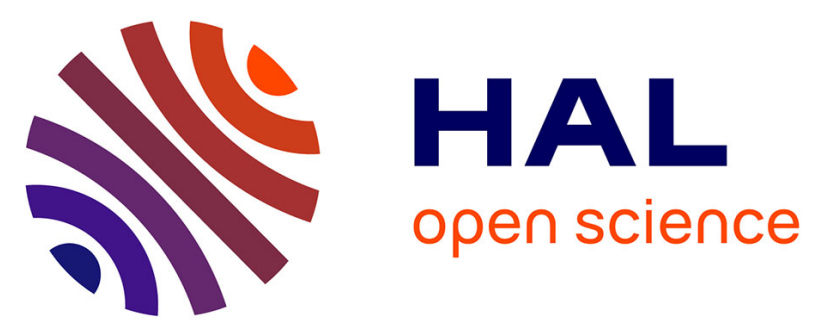

\title{
Isoprene-Styrene Chain Shuttling Copolymerization Mediated by a Lanthanide Half-Sandwich Complex and a Lanthanidocene: Straightforward Access to a New Type of Thermoplastic Elastomers
}

Andreia Valente, Grégory Stoclet, Fanny Bonnet, Andre Mortreux, Marc

Visseaux, Philippe Zinck

\section{To cite this version:}

Andreia Valente, Grégory Stoclet, Fanny Bonnet, Andre Mortreux, Marc Visseaux, et al.. IsopreneStyrene Chain Shuttling Copolymerization Mediated by a Lanthanide Half-Sandwich Complex and a Lanthanidocene: Straightforward Access to a New Type of Thermoplastic Elastomers. Angewandte Chemie International Edition, 2014, 53 (18), pp.4638-4641. 10.1002/anie.201311057 . hal-03379754

\author{
HAL Id: hal-03379754 \\ https://hal.univ-lille.fr/hal-03379754
}

Submitted on 15 Oct 2021

HAL is a multi-disciplinary open access archive for the deposit and dissemination of scientific research documents, whether they are published or not. The documents may come from teaching and research institutions in France or abroad, or from public or private research centers.
L'archive ouverte pluridisciplinaire HAL, est destinée au dépôt et à la diffusion de documents scientifiques de niveau recherche, publiés ou non, émanant des établissements d'enseignement et de recherche français ou étrangers, des laboratoires publics ou privés. 


\title{
Isoprene-styrene chain shuttling copolymerization mediated by lanthanide half-sandwich complex and lanthanidocene: a straightforward access to a new type of thermoplastic elastomers ${ }^{* *}$
}

\author{
Andreia Valente, Gregory Stoclet, Fanny Bonnet, André Mortreux, Marc Visseaux and Philippe \\ Zinck*
}

A lanthanide half-sandwich complex and a ansa lanthanidocene have been assessed for isoprene-styrene chain shuttling copolymerization with $n$-butylethylmagnesium (BEM). In the presence of 1 equiv. BEM, a fully amorphous multiblock microstructure of soft and hard segments is achieved. The microstructure consists of poly(isoprene-co-styrene) blocks, with hard blocks rich in styrene and soft blocks rich in isoprene. The composition of the blocks and the resulting glass transition temperatures $\left(\mathrm{T}_{\mathrm{g}}\right)$ can be easily modified by changing the feed and/or the relative amount of the catalysts, highlighting a new class of thermoplastic elastomers (TPEs) with tunable transition temperatures. The materials self-organize into nanostructures at the solid state.

TPEs are materials that exhibit an elastic behavior similar to that of vulcanized rubber. ${ }^{[1]}$ In contrast to thermosets elastomers, they possess thermoreversible crosslinks and can be processed as thermoplastics. TPEs are widely used to improve the properties of rigid thermoplastics, notably their impact strength. TPEs in the form of block copolymers can furthermore self-assemble in the solid state or in solution, leading to nanostructures with a variety of properties and potential functions. ${ }^{[2]}$ Poly(styrene-co-butadiene-co-styrene) triblock copolymers have been commercialized and are used as bitumen additives and viscosity modifiers. ${ }^{[2-3]}$ The polybutadiene block shows a glass transition temperature below room temperature, providing the elastomeric character or soft block, while polystyrene with a $T_{g}$ above room temperature acts as the crosslink or hard block. Di- and triblocks copolymers are formed by anionic polymerization, ${ }^{[1]}$ while multiblock microstructures of homopolymers can be obtained by chain shuttling copolymerization (see vide infra). ${ }^{[4 d]}$ These blocky structures show well defined transition temperatures $\left(T_{g}\right.$ or melting temperature of the homopolymers) that cannot be tuned, which restricts their fields of application. An approach able to tune the transition temperatures of the blocks may widen the applications of these materials to other

[*] Dr. A. Valente, Dr. F. Bonnet, Prof. A. Mortreux, Prof. M. Visseaux, Prof. P. Zinck

Unity of Catalysis and Solid State Chemistry, CNRS,

University Lille 1, Science and Technology, 59655

Villeneuve d'Ascq, France

philippe.zinck@univ-lille1.fr

Dr G. Stoclet

Unité Matériaux Et Transformations, CNRS, University

Lille1, Science and Technology, 59655 Villeneuve d'Ascq, France

[**] This work was supported by the French Ministry of Education and Research. The authors acknowledge Aurélie Malfait for technical assistance.

Supporting information for this article is available on the WWW under http://www.angewandte.org or from the author fields including for example shape memory polymers. The synthesis of such adjustable structures is not an easy task and requires the use of advanced synthetic methods.

Chain shuttling polymerization ${ }^{[4]}$ is a process based on coordinative chain transfer polymerization ${ }^{[5-6]}$ that gives access to multiblock microstructures (Scheme 1). The growing macromolecular chain is allowed to "shuttle" between two catalysts presenting a difference in monomer selectivity via a chain transfer agent. Our objective in this study was to extend the potentialities of chain shuttling copolymerization to the synthesis of a new class of thermoplastic elastomers with variable transition temperatures. As the $T_{g}$ of statistical copolymers can be easily varied by a change of their composition, a fully amorphous multiblock microstructure consisting of hard and soft statistical copolymers was targeted. We developed these last years lanthanide half-sandwich complexes based catalytic systems for the coordinative chain transfer polymerization and copolymerization of conjugated dienes, styrene and 1-alkenes. ${ }^{[6]} \mathrm{We}$ elaborated our strategy based on this knowledge. Borohydrido half-lanthanidocenes are known to lead to isoprene rich poly(isoprene-co-styrene) copolymers with a high 1,4trans stereoselectivity when combined to magnesium dialkyls. We envisioned the use of a sterically hindered complex as second precatalyst in order to reach styrene rich poly(isoprene-co-styrene) blocks. Lanthanum and neodymium based pre-catalysts were found to be particularly well suited for the reversible transmetalation of a growing polymeric chain with magnesium dialkyls. We report herein the first example of a chain shuttling copolymerization

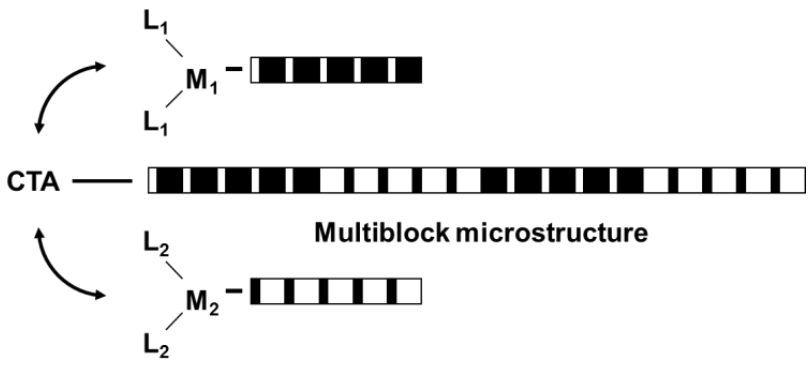

Scheme 1. Chain shuttling copolymerization. $M_{i}$ represents transition metals or lanthanides allowing propagation, $L_{i}$ ligands, and CTA the chain transfer or chain shuttling agent.
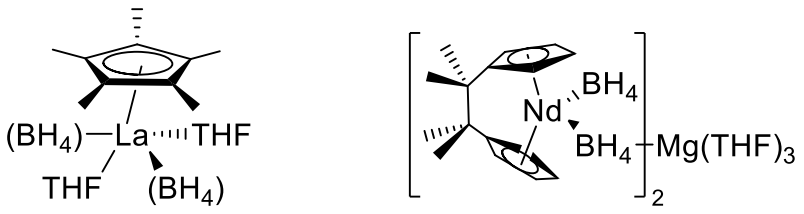

Scheme 2. Pre-catalysts used in this study. 
Table 1. Isoprene-styrene statistical and chain shuttling copolymerizations using $\mathbf{1}$ and $\mathbf{2}$ in combination with BEM

\begin{tabular}{|c|c|c|c|c|c|c|c|c|c|c|c|c|c|c|}
\hline \multirow[t]{2}{*}{ Entry $^{[a]}$} & \multirow{2}{*}{$\begin{array}{c}\text { Pre- } \\
\text { Catalysts } \\
\mathbf{1 / 2}\end{array}$} & \multirow[t]{2}{*}{ Ip/St } & \multirow{2}{*}{$\begin{array}{l}\mathrm{Mg} \\
\text { Eq. }\end{array}$} & \multirow{2}{*}{$\begin{array}{l}\text { Time } \\
\text { (h) }\end{array}$} & \multirow{2}{*}{$\begin{array}{l}\text { Yield } \\
(\%)\end{array}$} & \multirow{2}{*}{$\begin{array}{c}M_{n}{ }^{[b]} \\
(g / m o l)\end{array}$} & \multirow[t]{2}{*}{$D_{M}{ }^{[b]}$} & \multirow{2}{*}{$\begin{array}{l}\text { Ip } \\
(\%)\end{array}$} & \multirow{2}{*}{$\begin{array}{l}\mathrm{St}^{[\mathrm{cc}]} \\
(\%)\end{array}$} & \multicolumn{3}{|c|}{$\begin{array}{c}\text { Polyisoprene } \\
\text { microstructure }{ }^{[\mathrm{c}]} \\
\end{array}$} & \multirow{2}{*}{\multicolumn{2}{|c|}{$\begin{array}{l}\mathrm{Tg} \\
\left({ }^{\circ} \mathrm{C}\right)\end{array}$}} \\
\hline & & & & & & & & & & $\begin{array}{c}\text { 1,4-trans } \\
(\%)\end{array}$ & $\begin{array}{c}1,4 \text {-cis } \\
(\%)\end{array}$ & $\begin{array}{l}3,4 \\
(\%)\end{array}$ & & \\
\hline 1 & $100 / 0$ & $50 / 50$ & 1 & 2 & 48 & 45200 & 1.3 & 88 & 12 & 98 & - & 2 & -50 & \\
\hline 2 & $100 / 0$ & $50 / 50$ & 10 & 40 & 58 & 8100 & 1.8 & 68 & 32 & 84 & - & 16 & -26 & \\
\hline 3 & $0 / 100$ & $50 / 50$ & 1 & 2 & 5 & 9400 & 1.3 & 50 & 50 & 100 & - & - & nd & \\
\hline 4 & $0 / 100$ & $50 / 50$ & 1 & 24 & 26 & 45300 & 1.6 & 50 & 50 & 100 & - & - & 5 & \\
\hline 5 & $0 / 100$ & $50 / 50$ & 10 & 30 & 79 & 10700 & 1.8 & 48 & 52 & 100 & - & - & 2 & \\
\hline 6 & $50 / 50$ & $50 / 50$ & 1 & 2 & 8 & 23200 & 1.4 & 70 & 30 & 100 & - & - & nd & \\
\hline 7 & $50 / 50$ & $50 / 50$ & 1 & 24 & 68 & 62300 & 2.1 & 61 & 39 & 100 & - & - & -15 & 41 \\
\hline 8 & $50 / 50$ & $50 / 50$ & 3 & 24 & 76 & 33800 & 2.3 & 55 & 45 & 100 & - & - & 0 & \\
\hline 9 & $50 / 50$ & $50 / 50$ & 5 & 24 & 75 & 19800 & 2.0 & 52 & 48 & 100 & - & - & -2 & \\
\hline 10 & $50 / 50$ & $50 / 50$ & 10 & 26 & 72 & 10000 & 1.8 & 62 & 38 & 92 & - & 8 & -10 & \\
\hline 11 & $50 / 50$ & $30 / 70$ & 1 & 2 & 11 & 25700 & 1.2 & 60 & 40 & 96 & 4 & - & -10 & 34 \\
\hline 12 & $50 / 50$ & $30 / 70$ & 1 & 24 & 61 & 60600 & 2.3 & 56 & 44 & 94 & 6 & - & -3 & 31 \\
\hline 13 & $50 / 50$ & $70 / 30$ & 1 & 18 & 84 & 82700 & 1.6 & 76 & 24 & 99 & 1 & - & -35 & 36 \\
\hline 14 & $30 / 70$ & $50 / 50$ & 1 & 24 & 74 & 80400 & 1.7 & 62 & 38 & 100 & - & - & -10 & 40 \\
\hline 15 & $10 / 90$ & $50 / 50$ & 1 & 24 & 62 & 85900 & 1.8 & 58 & 42 & 100 & - & - & -2 & 36 \\
\hline 16 & $70 / 30$ & $50 / 50$ & 1 & 24 & 67 & 80200 & 1.6 & 69 & 31 & 100 & - & - & -27 & \\
\hline
\end{tabular}

[a] Reactions conducted at $50^{\circ} \mathrm{C}$ in toluene for a monomers / pre-catalyst(s) ratio of 2000 (e.g $1.1 \mathrm{ml}$ styrene $\left(10^{-2} \mathrm{~mol}\right)$ and $1 \mathrm{ml}$ isoprene $\left(10^{-2}\right.$ $\mathrm{mol}$ ) in $1.5 \mathrm{ml}$ toluene for a 50/50 molar ratio of the monomers). The chain shuttling copolymerizations were conducted with a 50/50 molar ratio of the pre-catalysts. [b] Number-average molecular weight and dispersity determined by size exclusion chromatography using polystyrene standards. [c] from ${ }^{1} \mathrm{H}$ NMR measurements.

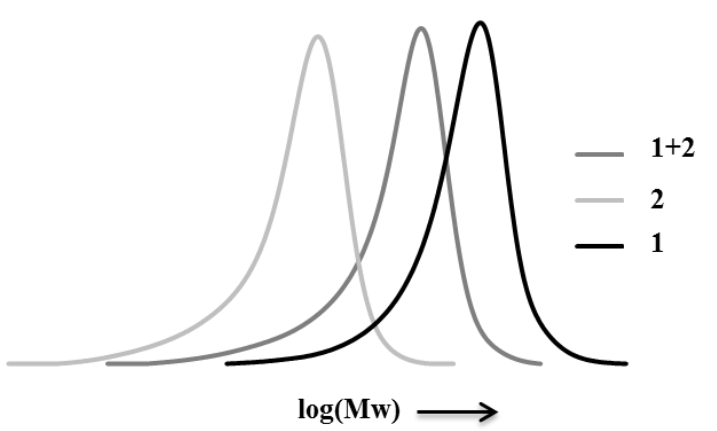

Figure 1. Molecular weight distributions obtained by size exclusion chromatography after $2 \mathrm{~h}$ reaction (entries 1,3 and 6 ).

leading to a fully amorphous multiblock microstructure of soft and hard statistical copolymers, providing a straightforward access to a new class of thermoplastic elastomers with variable transition temperatures. Isoprene and styrene were selected as monomers, the lanthane half-sandwich complex $\mathrm{Cp} * \mathrm{La}\left(\mathrm{BH}_{4}\right)_{2}(\mathrm{THF})_{2} \quad$ (1) $\left(\mathrm{Cp}^{*}=\mathrm{C}_{5} \mathrm{Me}_{5}\right)$ and the ansa-neodymocene $\left[\left(\mathrm{C}_{5} \mathrm{H}_{4} \mathrm{CMe}\right)_{2} \mathrm{Nd}\left(\mathrm{BH}_{4}\right)_{2}\right]_{2} \mathrm{Mg}(\mathrm{THF})_{3}$ (2) as pre-catalysts (Scheme 2) and $n$-butylethylmagnesium as chain transfer agent.

Experiments representative of the statistical copolymerization of isoprene and styrene (50/50 molar ratio) conducted in the presence of either 1 or 2 combined to 1 and 10 eq. BEM are presented in Table 1, entries 1-5. The decrease of the number-average molecular weight observed for 10 eq. BEM vs. 1 eq. shows that the transmetalation is occurring efficiently with both pre-catalysts. Statistical copolymers with a unique Tg and monomodal molecular weight distributions are obtained. 1 leads to isoprene rich statistical copolymers exhibiting a low $\mathrm{Tg}$, while the copolymers obtained with 2 show higher styrene content and higher $T_{g}$. The chromatograms reveal a monomodal distribution of the molecular weight in all cases.

Chain shuttling experiments were first conducted with a 50/50 molar ratio of the monomers and a 50/50 molar ratio of the catalysts (entries 6-10, Table 1). NMR investigations of possible ligand exchange were conducted prior to polymerization, and no ligand exchange between the two complexes was observed in benzene- $d 6$ after several hours at $50^{\circ} \mathrm{C}$, before and after introduction of 10 eq. BEM. The decrease of the number-average molecular weight with increasing quantities of BEM shows that the transmetalation is occurring efficiently. The copolymer obtained using $\mathbf{1}+\mathbf{2}$ and 1 eq. BEM exhibits an overall composition comprised between those obtained using $\mathbf{1}$ and $\mathbf{2}$ alone (39\% styrene inserted in the copolymer vs. 12 and 50\%, respectively) and a highly 1,4-trans microstructure of the polyisoprene part. The occurrence of chain shuttling between the two catalysts was assessed from the chromatograms obtained after $2 \mathrm{~h}$ reactions (Figure 1). The molecular weight distribution of the copolymer obtained by chain shuttling is monomodal, and located between those obtained using $\mathbf{1}$ and $\mathbf{2}$ alone. The resulting polymer is characterized by two $\mathrm{T}_{\mathrm{g}}$, the lower one being ascribed to the glass transition of isoprene rich blocks and the higher one to styrene rich blocks. Such characteristics are typical of thermoplastic elastomers. Endothermic peak resulting from the melting of polyisoprene crystalline phase could not be observed, confirming the amorphous nature of the materials. The formation of the multiblock microstructure was confirmed by fractionation experiments showing that the reaction product is not a mixture of the copolymers made by $\mathbf{1}$ and $\mathbf{2}$ separately (see supporting information). Additionally, the blend of the copolymers made by $\mathbf{1}$ and 2 separately shows a phase separation (figure SI1), while the copolymers formed by chain shuttling are fully transparent (see a typical example in figure 2).

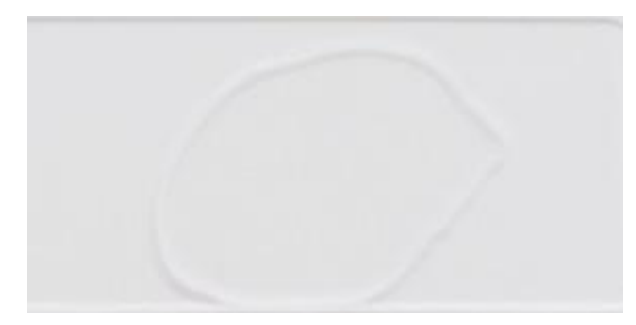

Figure 2. Entry 7 cast onto a glass slide (picture) 
Chain shuttling copolymerizations were further conducted in the presence of increasing amounts of BEM (Table 1, entries 8-10). A unique $\mathrm{T}_{\mathrm{g}}$ was observed for these copolymers, showing that the microstructure has shifted from a thermoplastic elastomer material to a more conventional statistical copolymer. In the presence of excess BEM, the transmetalation does not allow sufficient chain growth on each of the catalysts to afford the multiblock microstructure. Keeping in mind that substantial quantities of chain shuttling agent are usually required for the formation of the multiblock microstructure via chain shuttling polymerization, it is noteworthy that we achieve this goal with only 1 eq. Chain shuttling copolymerizations experiments conducted in the presence of 1 eq. BEM with excess styrene (entries 11-12) and excess isoprene (entry 13) in the feed are presented in Table 1. Two $T_{g}$ are also observed for these materials, highlighting again the formation of the multiblock microstructure. The influence of the catalyst ratio was further assessed (entries 14-16). If an excess of 2 leads to the desired multiblock microstructure, the copolymer resulting from the reaction conducted with $70 \%$ of $\mathbf{1}$ shows only one $\mathrm{T}_{\mathrm{g}}$. It is noteworthy that both the modification of the feed and that of the relative amount of the catalysts lead to a variation of both $\mathrm{T}_{\mathrm{g}}$.

The nanostructure of the copolymers was investigated by means of Small-Angle X-ray Scattering (SAXS). A scattering contrast could be observed only for samples exhibiting the multiblock microstructure (see typical examples in Figure SI2). The scattering curves could be modeled by a dispersion of dilute disks having an average thickness of $6 \pm 1 \mathrm{~nm}$. From a structural point of view this can be interpreted by the self-assembly of one of the blocks into lamellas. The dilute term of the model indicates furthermore that the lamellas are non-interacting or in other words that there is no nanostructuration of the lamellas at large scale.
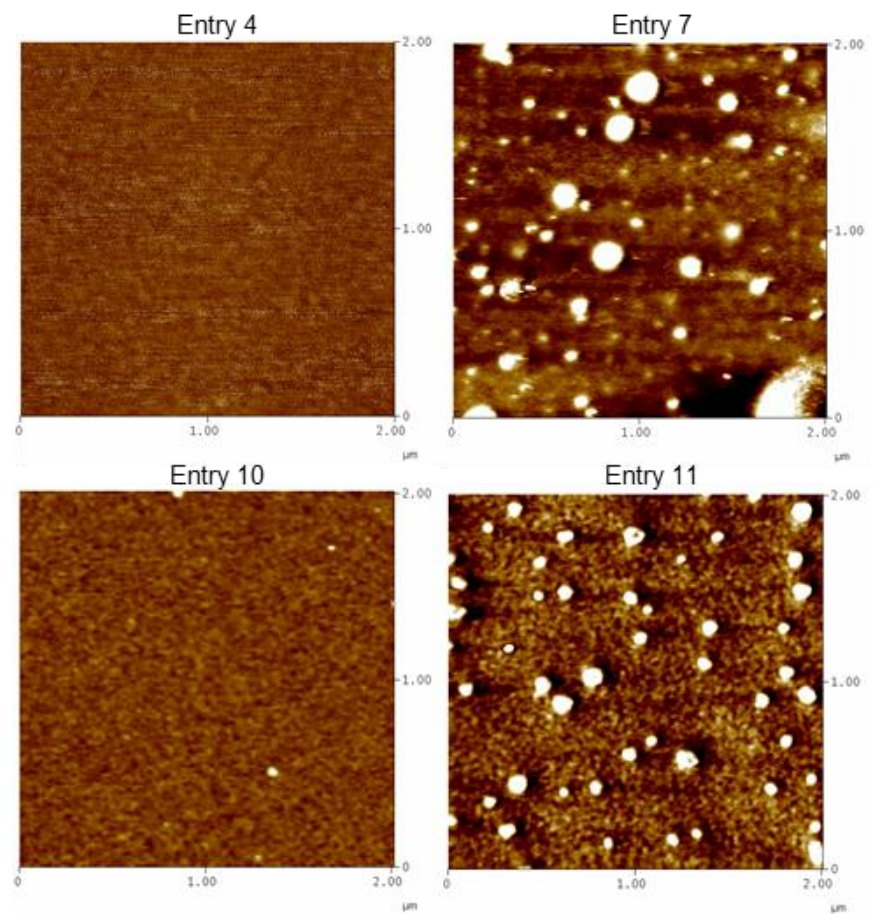

Figure 3. AFM phase contrast images of entries 4, 7, 10 and 11 $\left(\right.$ Zscale $\left.=20^{\circ}\right)$

Atomic Force Microscopy (AFM) analyses were performed to pursue the investigation of the nanostructure (Figure 3). In the presence of $\mathbf{1}$ or $\mathbf{2}$ alone, when a random copolymer is formed, a uniform structure is observed (entry 4 in Figure 3). The nanostructuration of the samples resulting from chain shuttling copolymerization in the presence of 1 eq. BEM can be seen Figure 3 , entries 7 and 11. Assuming that bright domains are assigned to hard domains, the nanodomains correspond to a self-assembly of the rigid blocs. AFM line profile analysis (Figure SI3) shows that the top of the hard domains is flat, indicating a disk-like shape. The height of the disks around $9 \mathrm{~nm}$ is in good agreement with the values obtained from SAXS. Finally, the examination of a sample synthesized by chain shuttling with a higher amount of BEM amount (entry 10 in Figure 3) does not evidence the presence of disk like nanodomains. This is in agreement with the thermal properties of this material for which only one $\mathrm{T}_{\mathrm{g}}$ was detected as expected for a random copolymer structure.

In summary, we report a synthetic approach affording a straightforward access to an unprecedented fully amorphous multiblock microstructure of soft and hard statistical copolymers. The microstructure consists of blocks of poly(isoprene-co-styrene) copolymers, with hard blocks rich in styrene and soft blocks rich in isoprene. The $\mathrm{T}_{\mathrm{g}}$ of the blocks can be varied simply by changing the feed or the relative amount of the catalysts, and the resulting copolymers self-organize into nanostructures. Additional work is currently in progress to explore the potential applications of these new block copolymers.

Received: ((will be filled in by the editorial staff))

Published online on ((will be filled in by the editorial staff))

Keywords: Chain Shuttling · Coordinative Chain Transfer Polymerization · Block Copolymers · Copolymerization

[1] J.G. Drobny, Handbook of thermoplastic elastomers, William Andrew Publishing, New York, 2007.

[2] F.X. Schacher, P.A. Rupar, Angew. Chem, 2012, 124, 8020-8044; Angew. Chem, Int. Ed. 2012, 51, 7898-7921

[3] a) K. Knoll, N. Nießner, Macromol. Symp. 1998, 132, 231 - 243; b) http://www.kraton.com/; c) A.-V. Ruzette, L. Leibler, Nat. Mater. $\mathbf{2 0 0 5}, 4,19-31$.

[4] a) D.J. Arriola, E.M. Carnahan, P.D. Hustad, R.L. Kuhlman, T.T. Wenzel, Science, 2006, 312, 714-719; b) R.L. Kuhlman, J. Klosin, Macromolecules, 2010, 43, 7903-7904; c) J. Wei, W. Zhang, R. Wickham, L. R. Sita, Angew. Chem., 2010, 122, 9326-9330; Angew. Chem. Int. Ed., 2010, 49, 9140-9144; d) L. Pan, K. Zhang, M. Nishiura, Z. Hou, Angew. Chem., 2011, 123, 12218-12221; Angew. Chem. Int. Ed., 2011, 50, 12012-12015; e) F. Alfano, H.W. Boone, V. Busico, R. Cipullo, J.C. Stevens., Macromolecules, 2007, 40, 77367738; f) A. Xiao, L. Wang, Q. Liu, H. Yu, J. Wang, J. Huo, Q. Tan, J. Ding, W. Ding, A.M. Amin, Macromolecules, 2009, 42, 1834-1837; g) M. Zintl, B. Rieger, Angew. Chem., 2007, 119, 337 - 339; Angew. Chem. Int. Ed., 2007, 46, 333 - 335; h) C. Descour, T.J.J. Sciarone, D. Cavallo, T. Macko, M. Kelchtermans, I. Korobkov, R. Duchateau, Polym. Chem., 2013, 4, 4718-4729.

[5] a) J.F. Pelletier, A. Mortreux, X. Olonde, K. Bujadoux, Angew. Chem., 1996, 108, 1980-1982; Angew. Chem. Int. Ed. Engl. 1996, 35, 1854 1856; b) G. J. P. Britovsek, S. A. Cohen, V.C. Gibson, M. van Meurs, J. Am. Chem. Soc., 2004, 126, 10701-10712.; c) W. P. Kretschmer, A. Meetsma, B. Hessen, T. Schmalz, S. Qayyum, R. Kempe, Chem. Eur. J., 2006, 12, 8969-8978; d) R. Kempe. Chem. Eur. J., 2007, 13, 27642773 and references herein; e) P.D. Hustad, R.L. Kuhlman, D.J. Arriola, E.M. Carnahan, T. T. Wenzel, Macromolecules, 2007, 40, 7061-7064; f) S.B. Amin, T.J. Marks, Angew. Chem., 2008, 120 , 2034-2054; S.B. Amin, T.J. Marks, Angew. Chem. Int. Ed., 2008, 47, 2006-2025; g) J. Wei, W. Zhang, L.R. Sita, Angew. Chem., 2010, 122, 1812-1816; Angew. Chem. Int. Ed. Engl. 2010, 47, 1768-1772 ; h) L. Annunziata, A.-S. Rodrigues, E. Kirillov, Y. Sarazin, J. Okuda, L. Perrin, L. Maron, J.-F. Carpentier, Macromolecules, 2011, 44, 3312- 
3322; i) A. Valente, A. Mortreux, M. Visseaux, P. Zinck, Chem. Rev., 2013, 113, 3836-3857 and references herein.

[6] a) P. Zinck, A. Valente, F. Bonnet, A. Violante, A. Mortreux, M. Visseaux, S. Ilinca, R. Duchateau, P. Roussel, J. Polym. Sci. Polym. Chem, 2010, 48, 802-814; b) A. Valente, P. Zinck, A. Mortreux, M. Vitorino, M. Visseaux, J. Polym. Sci. Polym. Chem, 2010, 48, 46404647; c) A. Valente, P. Zinck, A. Mortreux, M. Visseaux, J. Polym.
Sci. Polym. Chem, 2011, 49, 1615-1620; d) A. Valente, P. Zinck, A. Mortreux, M. Bria, M. Visseaux., J. Polym. Sci. Polym. Chem, 2011, 49, 3778-3782 ; e) S. Loughmari, A. Hafid, A. Bouazza, A.E. Bouadili, P. Zinck, M. Visseaux, J. Polym. Sci., Polym. Chem, 2012, 50, 28982905; f) P. Zinck, Polym. Int. 2012, 61, 2-5; g) A. Ventura, T. Chenal, M. Bria, F. Bonnet, P. Zinck, Y. Ngono-Ravache, E. Balanzat, $\quad$ M. Visseaux, Eur. Polym. J. 2013, 49, 4130-4140. 


\section{Entry for the Table of Contents}

Layout 2:

\section{Block copolymerization}

A. Valente, G. Stoclet, F. Bonnet, A. Mortreux, M. Visseaux, P. Zinck* Page Page

Isoprene-styrene chain shuttling copolymerization mediated by lanthanide half-sandwich complex and lanthanidocene: a straightforward access to a new type of thermoplastic elastomers
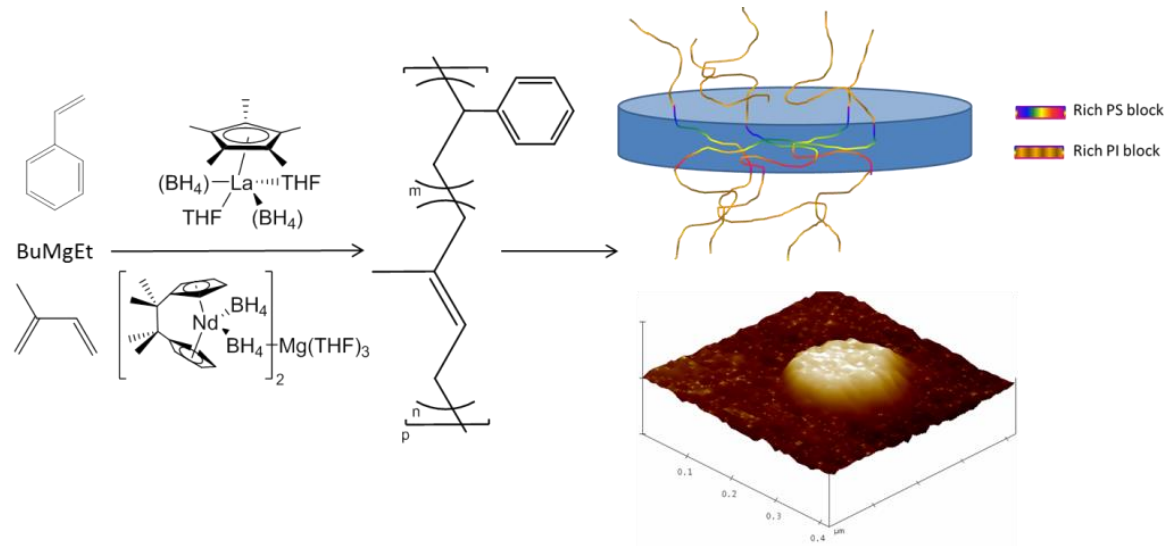

Chain shuttling copolymerization of isoprene and styrene using a borohydrido lanthane half-sandwich complex, a borohydrido ansa-neodymocene and a magnesium dialkyl affords direct access to new amorphous thermoplastic elastomers. The resulting multiblock microstructure of soft and hard statistical copolymeric segments self-assembles at the nanoscale. 